\title{
Liberalizing Trade in Environmental Goods and Services
}

Bouwe R. Dijkstra ${ }^{1}$

Anuj J. Mathew ${ }^{2}$

May 2015

\begin{abstract}
We examine the effects of trade liberalization in environmental goods in a model with one domestic downstream polluting firm and two upstream firms (one domestic, one foreign). The upstream firms offer their technologies to the downstream firm at a flat fee. The domestic government sets the emission tax rate after the outcome of $R \& D$ is known. The effect of liberalization on the domestic upstream firm's R\&D incentive is ambiguous. Liberalization usually results in cleaner production, which allows the country to reach higher welfare. However this increase in welfare is typically achieved at the expense of the environment (a backfire effect).
\end{abstract}

JEL Classification: F12, F18, L24, O32, Q55, Q58

Keywords: Eco-industry, R\&D, trade and environment, trade liberalization, backfire effect

\footnotetext{
${ }^{1}$ Corresponding author. GEP and School of Economics, University of Nottingham, Nottingham NG7 2RD, UK, tel. +44 115 8467205, fax +44 115 9514159, email bouwe.dijkstra@nottingham.ac.uk; CESifo, Munich.

${ }^{2}$ Government Economic Service (UK): Ministry of Justice, London.
} 


\section{Introduction}

While trade liberalization of past sixty years has brought great economic growth, recent research suggests it may have harmed the environment. ${ }^{1}$ However, surely trade liberalization in environmental goods and services, making cleaner technologies more widely available especially in developing countries, must be good for the environment? This was the thinking at the fourth WTO Ministerial Conference at Doha (WTO, 2001), where "with a view to enhancing the mutual supportiveness of trade and environment", the conference agreed to negotiate on "the reduction or, as appropriate, elimination of tariff and non-tariff barriers to environmental goods and services". It instructed the Committee on Trade and Environment to give particular attention to "those situations in which the elimination or reduction of trade restrictions and distortions would benefit trade, the environment and development". This idea of a "win-win-win" solution is also strongly promoted by the OECD (2003, 2005).

So far, the Doha round has produced the so-called Bali agreement of December 2013, which does not include environmental goods. Shortly after the Bali agreement, representatives of many countries including the US, the EU, China and Japan, jointly representing $86 \%$ of world trade in environmental goods, pledged their commitment to work together and with other WTO Members to begin preparing for negotiations for reducing tariffs on environmental goods (USTR, 2014).

In this paper, we examine the effect of trade liberalization in environmental goods and services (EGS) on a country's EGS sector, ${ }^{2}$ its welfare and its environmental quality. Our analysis is especially relevant for developing countries where the demand for EGS is fast expanding, while the domestic sector is still immature ${ }^{3}$ and trade

\footnotetext{
${ }^{1}$ Antweiler et al. (2001) find that trade liberalization has generally reduced $\mathrm{SO}_{2}$ concentrations. Cole and Elliott (2003) suggest it will reduce BOD, but increase $\mathrm{CO}_{2}$ and $\mathrm{NO}_{x}$ emissions. Managi et al. (2009) conclude that trade has benefited the environment in OECD countries, but increased $\mathrm{SO}_{2}$ and $\mathrm{CO}_{2}$ emissions elsewhere. Lovely and Popp (2011) empirically examine two effects of trade openness: While it improves access to the latest clean technologies, it also reduces industry's ability to pass on regulatory costs to consumers.

${ }^{2}$ See Sinclair-Desgagné (2008) for a description of the global eco-industry.

${ }^{3}$ OECD (2005) predicts that the EGS market will grow by less than $1 \%$ annually in developed countries and by $8.6 \%$ in the developing countries, while Sinclair-Desgagné (2008) predicts growth figures of $3-5 \%$ and $10-15 \%$ respectively. In 2003 nearly $80 \%$ of the global exports of EGS originated in developed countries (Hamwey, 2005).
} 
barriers for EGS are relatively high (OECD, 2005; De Melo and Vijil, 2014).

We will model EGS as integrated technologies, reducing the emission-to-output ratio of production. ${ }^{4}$ We consider an industry where the downstream good's production is polluting and the upstream industry is engaged in R\&D to develop a cleaner technology which it can licence to the downstream firm. The upstream firm faces competition from a foreign firm after trade liberalization.

We find that the effect of trade liberalization on the incentive for domestic firm to do R\&D is ambiguous. Trade liberalization usually leads to the availability of cleaner technologies and higher welfare. However, this increase in welfare comes at the expense of the environment. ${ }^{5}$ The government responds to the opportunity for cleaner production by allowing more production, to the point where total pollution increases. Borrowing a term from the energy economics literature (Saunders, 2000), the availability of a cleaner technology causes a backfire effect. Thus we cast doubt on the "win-win-win" outcome that the WTO and OECD hope for: there seems to be a "win" both for welfare and trade, but not for environmental quality.

The rest of the paper is organized as follows. In Section 2 we review the relevant literature. After describing the model in Section 3, we solve the game by backwards induction. In Section 4 we analyze how the upstream firms set their technology fees under different possible R\&D outcomes. In Section 5, we look at government policy under free trade and autarky. Section 6 discusses the R\&D decisions of the firms. In Section 7 , we compare expected welfare and environmental damage under autarky and free trade. Section 8 concludes.

\section{Literature review}

The literature on innovation and adoption of new abatement technology, reviewed by Jaffe et al. (2003) and Requate (2005a), has mostly assumed that if a polluting firm wants to install a new abatement technology, it has to pay a certain installation or

\footnotetext{
${ }^{4}$ The definition of EGS has been a major stumbling block in the WTO negotiations so far (Zhang, 2013; De Melo and Vijil, 2014).

${ }^{5}$ In a different context, with heterogeneous firms and an exogenously fixed emission tax rate, Bréchet and Ly (2013) also show that the adoption of cleaner technology can increase pollution.
} 
(possibly) R\&D cost itself. Some authors take into account that one firm can license its invention to other firms. In the papers by Milliman and Prince (1989), Biglaiser and Horowitz (1995), Fischer et al. (2003), the innovator is one of the polluting firms. In other papers, which we will discuss here, there are specialized firms (the eco-industry) that licence their innovations or sell their products to the polluting industry. ${ }^{6}$

Parry $(1995,1998)$ sets up a model with free entry into the eco-industry. The probability that a given firm will find (and obtain a patent for) the new technology is decreasing in the number of eco-firms. Parry (1995) argues that when the government sets the emission tax rate before the eco-firms' entry decision, the tax rate will usually be below marginal damage. Parry (1998) compares emission taxes, tradable emission permits and relative standards, but only at their respective Pigouvian levels. This is to counter monopoly pricing by the innovator, excessive entry into the eco-industry and the excess of innovator revenue over social benefits. In the same vein, David et al. (2011) find that although raising the emission tax rate induces new abatement suppliers to enter the market, it might not increase abatement efforts. This is because with the stringent tax, the demand for the abatement goods becomes more price inelastic leading to eco-firms reducing their output.

Laffont and Tirole (1996) argue that the monopolistic innovator will set a licence fee that slightly undercuts the permit price set by the regulator. If the regulator sets the permit price after R\&D, she will set it equal to zero in order to obtain complete diffusion of the clean technology. As a result, the innovator's licence fee income will be zero, so that he will not invest in R\&D. Although the timing of our game is similar to Laffont and Tirole's (1996), we do not encounter the problem of incomplete diffusion, because there is only one firm to which the innovators license their technology.

Requate (2005b) models a monopolistic eco-firm's R\&D and licensing fee decisions for a number of timing and commitment regimes. Environmental policy (the tax rate or the number of tradable permits issued) is either set after the downstream firms' adoption decisions, after observing R\&D success but before adoption, or before R\&D, where it could be contingent on or independent of R\&D success. The author finds that

\footnotetext{
${ }^{6}$ All papers discussed here assume welfare-maximizing governments. See Canton (2008) for a political-economy model with the eco-industry in an international setting.
} 
commitment to a menu of tax rates dominates all other policy regimes. In our paper, we only model environmental taxation set after observing R\&D success but before adoption. We expand Requate's (2005b) model by including the downstream product market and competition between a domestic and a foreign eco-firm.

Perino (2010) includes the output market for the downstream industry and finds that optimal emissions, as well as emissions under tradable permits, can be decreasing in the cost of abatement. We find a similar result with a different model: Expected pollution rises when international trade results in the availability of cleaner technology.

We now turn to the literature on the eco-industry and international trade. All the papers we discuss here (unlike our own paper) model the eco-industry's product as an end-of-pipe technology, equivalent to an input into production, in the sense that the more the downstream firm uses of it, the lower its emissions. These papers usually do not consider the eco-industry's R\&D incentives. Our paper, on the other hand, assumes that the eco-industry provides an integrated abatement technology (reducing emissions per unit of output), which the downstream firm can either use (against a fee) or not use, and we analyze the eco-industry's R\&D incentives.

Feess and Muehlheusser (2002) consider an international Cournot duopoly with an eco-firm in the home country. Unlike in our model, Feess and Muehlheusser (2002) assume that the price of its product is exogenously given. The authors find that if the eco-firm benefits from a higher tax rate, the home goverment will set a higher tax rate than the foreign government. However, the home government may lower its tax rate when there is learning by doing.

Greaker (2006) shows how a country can increase the export market share of its (perfectly competitive) polluting industry by committing to a low level of allowed emissions per firm. This is because the stricter environmental policy leads more firms to pay the initial R\&D cost to enter the eco-industry. This increased competition in the eco-industry lowers the price of the environmental good.

Greaker and Rosendahl (2008) employ a two-country model with an eco-firm in each country, supplying the perfectly competitive polluting industries in both countries. The authors find that a more stringent environmental policy is good for the domestic 
polluting industry, because it reduces the price of abatement equipment. However, the increase in demand from the domestic polluting industry may benefit the foreign eco-firm at the expense of the domestic eco-firm.

In a framework similar to Greaker and Rosendahl (2008) but with a monopolistic Northern eco-firm, Nimubona (2012) shows that an import tariff on EGS helps the Southern government extract rents from the eco-firm. An exogenous decrease in the tariff leads to a lower emission tax in the South if the South cannot fully extract the eco-firm's rents. While EGS imports rise, the decrease in the tax rate results in higher production, so that pollution may actually increase. Like Nimubona (2012), we find that trade liberalization usually increases the expected cleanliness of production, but when it does, it also increases pollution. However, our model is quite different in that we model EGS as an integrated technology rather than end-of-pipe, we assume there is a Southern eco-firm that can undertake $\mathrm{R} \& \mathrm{D}$, and we model trade liberalization as a discrete jump from autarky to completely free trade rather than a marginal reduction in the tariff.

\section{The model}

We consider the market for a consumption good, for which domestic demand is given by $P=A-q$, with $P$ the product price, $q$ production and $A>0$. For simplicity, we assume there is only one domestic producer of the good (the downstream firm), ${ }^{7}$ with constant marginal cost of production $c$. We will normalize $A-c=1$, so that:

$$
P-c=1-q
$$

For simplicity, we assume that there is no international trade in this good. Production of the good is polluting. Environmental damage of emissions $E$ is:

$$
D(E)=\frac{1}{2} \lambda E^{2}
$$

The abatement technologies $d, h, f, n$ that the downstream firm might use are integrated technologies that result in a certain emissions-to-output ratio $e=E / q$. Tech-

\footnotetext{
${ }^{7}$ If there were multiple downstream firms, we would have to consider the upstream firms' incentives to increase revenue by licencing to a limited number of firms at a higher fee.
} 
nology $d$ is the technology that the downstream firm itself has developed. We normalize the emission-to-output ratio $e_{d}$ of this technology to one. The other technologies are owned by the upstream firms. The downstream firm can use them for a flat fee $F$.

The domestic (foreign) upstream firm has abatement technology $h(f)$ available, with $e_{f}<e_{h}<1$, i.e. the foreign upstream firm's technology is cleaner than the domestic upstream firm's, and both are cleaner than the downstream firm's own technology. We can interpret this as the downstream firm having made an imperfect imitation of the upstream firms' abatement technologies (Parry, 1995, 1998).

Both upstream firms can do R\&D into a new technology $n$ with $e_{n}<e_{f}$. Firm $j$ 's $(j=h, f)$ cost of $\mathrm{R} \& \mathrm{D}$ is $C^{j}$, with:

$$
C^{f}=\phi C^{h}, \quad \phi \leq 1
$$

and its probability of finding the new technology is $p^{j}\left(p^{h} \leq p^{f}\right)$. Thus the foreign upstream firm has (weakly) lower cost of finding the new technology and is (weakly) more likely to find it.

Each technology consists of know-how and possibly also abatement equipment. The equipment for technology $i$ can only be built by the firm supplying the technology, at cost $K_{i}$. We shall assume: ${ }^{8}$

$$
K_{h} \geq K_{f} \geq K_{n} \geq 0
$$

The foreign upstream firm can also licence its technology $i=f, n$ abroad, earning net revenue (fees minus production costs) of $R_{i}$, with $R_{n}>R_{f}>0$. We assume that the domestic upstream firm does not have the expertise to licence its technology abroad.

Environmental policy consists of an emission tax. The domestic government sets the tax rate $t$ at the level that maximizes domestic welfare.

We compare the regimes of autarky and free trade. With autarky, tariff and/or non-tariff barriers are so high that it is impossible or not profitable for the foreign upstream firm to offer its technology to the domestic downstream firm. With free trade, there are no barriers for the foreign upstream firm. The game under autarky is as follows:

\footnotetext{
${ }^{8}$ If $K_{i}=0$, technology $i$ is a blueprint that requires no equipment.
} 
1. The domestic upstream firm decides whether or not to do $R \& D$, and the outcome of $\mathrm{R} \& \mathrm{D}$ is observed.

2. The domestic government sets the emission tax rate.

3. The domestic upstream and downstream firms bargain over the fee for the upstream firm's technology.

4. The domestic upstream firm builds the equipment. The downstream firm sets its output level.

The game under free trade is:

1. The domestic and foreign upstream firms decide whether or not to do R\&D, and the outcome of $\mathrm{R} \& \mathrm{D}$ is observed.

2. The domestic government sets the emission tax rate.

3. The domestic and foreign upstream firms set their technology fees.

4. The downstream firm decides which abatement technology. The winning upstream firm builds the equipment. The downstream firm sets its output level.

We will solve for the subgame perfect Nash equilibrium of the two games.

\section{Licence fee and output decisions}

In this section, we will solve for stages 3 and 4 of the game, introducing some constraints we will have to impose on the parameters.

Using backwards induction, we start the analysis in stage 4 . For stages 2 to 4 , the superscript $s$ denotes the different scenarios, according to the technologies that are available. We will define the scenarios at the end of this section. The subscript $i$ denotes the technology that the downstream firm uses. The downstream firm's profit gross of the licence fee (and its own building cost $K_{d}$ if applicable) in scenario $s$ with technology $i$ is, from (1):

$$
\pi_{i}^{s}=\left(P-t e_{i}\right) q_{i}^{s}=\left(1-q_{i}^{s}-t e_{i}\right) q_{i}^{s}
$$


Differentiating (5) and solving for the profit-maximizing quantity $q_{i}^{s}$ yields:

$$
q_{i}^{s}=\frac{1-t e_{i}}{2}
$$

Substituting (6) into (5), we find the gross profit of the downstream firm as:

$$
\pi_{i}^{s}=\left[\frac{1-t e_{i}}{2}\right]^{2}=\left(q_{i}^{s}\right)^{2}
$$

Moving on to stage 3, denote the upstream firm with the most (least) efficient technology $e_{1}\left(e_{2}\right)$ by firm $1(2)$, i.e. $e_{1} \leq e_{2}{ }^{9}$

In autarky, the domestic upstream firm is always firm 1 and the downstream firm is firm 2. We model the game between the two firms to determine the fee $F^{s}$ as Nash bargaining where the upstream firm has bargaining power $\tilde{\alpha} \in(0,1]$. The outside payoffs are zero for the upstream firm and $\pi_{d}^{s}-K_{d}$ for the downstream firm. We shall assume that the downstream firm has a positive outside payoff, but it would prefer the domestic upstream firm's technology if the fee equalled the equipment building cost:

$$
\pi_{1}^{s}-K_{1}>\pi_{d}^{s}-K_{d}>0
$$

The Nash bargaining problem is then:

$$
\max _{F^{s}}\left(F^{s}-K_{1}\right)^{\tilde{\alpha}}\left(\pi_{1}^{s}-F^{s}-\pi_{d}^{s}+K_{d}\right)^{1-\tilde{\alpha}}
$$

The first order condition is:

$$
\tilde{\alpha}\left(F^{s}-K_{1}\right)^{\tilde{\alpha}-1}\left(\pi_{1}^{s}-F^{s}-\pi_{d}^{s}+K_{d}\right)^{1-\tilde{\alpha}}=(1-\tilde{\alpha})\left(F^{s}-K_{1}\right)^{\tilde{\alpha}}\left(\pi_{1}^{s}-F^{s}-\pi_{d}^{s}+K_{d}\right)^{\tilde{\alpha}}
$$

Solving for $F^{s}$ yields:

$$
F^{s}=\tilde{\alpha}\left(\pi_{1}^{s}-\pi_{d}^{s}+K_{d}\right)+(1-\tilde{\alpha}) K_{1}>K_{1}
$$

where the inequality follows from (8).

\footnotetext{
${ }^{9}$ In order to avoid complications with corner solutions, we wish to restrict our parameters such that $q_{2}^{s}>0$. We derive the appropriate restrictions in Appendix A. Note that $q_{2}^{s}>0$ implies $q_{1}^{s}>0$, since $q_{1}^{s} \geq q_{2}^{s}$ by (6) and $e_{1} \leq e_{2}$.
} 
With free trade, firms 1 and 2 are the upstream firms. They engage in price competition to sell their technology to the downstream firm. ${ }^{10}$ In the Nash equilibrium, firm 2's fee will exactly cover its production cost $K_{2}$, while firm 1 charges a fee of:

$$
F^{s}=\pi_{1}^{s}-\pi_{2}^{s}+K_{2} \geq K_{1}
$$

with $\pi_{i}^{s}, i=1,2$, given by (7). The inequality follows from (4) and (7) with $e_{1} \leq e_{2}$. Strictly speaking, the downstream firm is then indifferent between the technologies offered by the two firms. We assume that the downstream firm will choose firm 1's technology. This is because firm 1 could always charge slightly less than $F^{s}$ in (10) to make the downstream firm prefer its technology.

The net profit $\Pi^{s}$ of the downstream firm (net of the licence fee for the efficient technology) is then, from (9) and (10):

$$
\Pi^{s}=\pi_{1}^{s}-F^{s}=\alpha\left(\pi_{2}^{s}-K_{2}\right)+(1-\alpha)\left(\pi_{1}^{s}-K_{1}\right)
$$

with $\pi_{i}^{s}, i=1,2$, given by (7) and $\alpha=\tilde{\alpha}$ (1) for autarky (free trade).

Firm 1's net fee (net of production cost) is:

$$
R^{s} \equiv F^{s}-K_{1}
$$

We show in Appendix B that the licence fee is first increasing and then decreasing in the quality of the superior technology. From (6), (7) and (10):

$$
\frac{d F^{s}}{d e_{1}}=-\alpha t^{s} q_{1}^{s}+\alpha\left[E_{2}^{s}-E_{1}^{s}\right] \frac{d t^{s}}{d e_{1}}
$$

An improvement in the best technology (a decrease in $e_{1}$ ) has two effects on the licence fee. Firstly, for a given tax rate, it increases the profits the downstream firm can obtain and thus raises the fee. This is the first term on the RHS of (13). Secondly, the tax rate changes, with the effect on $F^{s}$ given by the second term on the RHS of (13), where $E_{2}^{s}>E_{1}^{s}$. Initially, the tax rate might increase as the technology gets better. This would cause a further increase in the fee. However, eventually the tax rate will

\footnotetext{
${ }^{10}$ Price competition can be seen as the process that endogenizes bargaining power, resulting in complete (no) bargaining power for firm 1 (2) vis-a-vis the downstream firm.
} 
start to decline, which has a negative effect on the fee. Eventually, the second effect dominates as the tax rate and the fee decline to zero.

We restrict our analysis to a level of abatement technology such that the licence fee is decreasing in $e_{1}$ :

$$
\frac{d F^{s}}{d e_{1}}<0
$$

If instead $d F^{s} / d e_{1}>0$, the upstream firm would realize that it could gain a higher fee with a worse technology. This would give the firm an incentive to tinker with or sabotage the technology, increasing its $e_{1}$ and gaining a higher licence fee. We discuss the conditions for (14) to hold in Appendix B.

Finally, let us define the scenarios. In autarky, the scenarios are $n d$ and $h d$ when the domestic upstream firm has and has not found the new technology $n$ respectively. In both scenarios, the downstream firm chooses to use the domestic upstream firm's technology. With free trade, the scenarios with their equilibrium outcomes are:

- $f h$ : Neither the domestic nor the foreign firm has found the new technology. Then the foreign firm will supply technology $f$ to the downstream firm.

- $n h$ : Only the foreign firm has found the new technology. The foreign firm will supply $n$ to the downstream firm.

- $n f$ : Only the domestic firm has found the new technology. The domestic firm will supply $n$ to the downstream firm.

- $n n$ : Both firms have found the new technology. They compete the fee down to $K_{n}$. The domestic firm is indifferent between the two upstream firms' offers.

\section{Government Policy}

In stage two of the game, the goverment sets the emission tax rate that maximizes domestic welfare $W^{s}$ in scenario $s$, given that the domestic firm uses the most efficient technology $e_{1}$. Social welfare is the sum of the domestic upstream and downstream firms' profits, consumer surplus and tax revenues, minus environmental damage (2):

$$
W^{s}=\Pi^{s}+F_{h}^{s}+\frac{1}{2}\left[q_{1}^{s}\right]^{2}+t e_{1} q_{1}^{s}-\frac{1}{2} \lambda\left[e_{1} q_{1}^{s}\right]^{2}-\delta K_{1}
$$


where $\delta$ is an indicator variable equal to 1 (0) when the domestic (foreign) upstream firm supplies the abatement technology.

When $e_{1}$ is high, the government will want to set a positive tax rate in order to reduce pollution. When $e_{1}$ is low, the government would like to set a negative tax rate in order to correct for under-production by the monopolist downstream firm. In our analysis, we will exclude from our analysis values of $e_{1}$ so low that $t$ becomes negative. Indeed, as we have announced in Section 4, we will even exclude higher $e_{1}$ values for which $t$ is positive, but the licence fee is increasing in $e_{1}$.

With the emissions-to-output ratio given, welfare only depends on $q_{1}^{s}$ if the domestic firm supplies the technology. In that case, the government can reach the first best with the single instrument of the emission tax. There would be no welfare gain from using another instrument such as an output subsidy. If the foreign firm supplies the technology, welfare depends on $q_{2}^{s}$ as well as on $q_{1}^{s}$ and the government would gain from having another instrument (such as an output subsidy) available. However, since output subsidies are less commonly applied in manufacturing industries, we shall limit our analysis to the single instrument of an emission tax.

\section{$5.1 \quad$ Autarky}

Denote the domestic upstream firm's technology in stage 3 by $i, i=h, n$. With $e_{1}=$ $e_{i}, \Pi^{i d}+F_{h}^{i d}=\pi_{i}^{i d}$ by (11). Substituting this, (6) and (7) into (15), social welfare in scenario $i d$ is given by:

$$
W^{i d}=\left[\frac{1-t e_{i}}{2}\right]^{2}+\frac{1}{2}\left[\frac{1-t e_{i}}{2}\right]^{2}+t e_{i}\left(\frac{1-t e_{i}}{2}\right)-\frac{1}{2} \lambda\left[e_{i}\left(\frac{1-t e_{i}}{2}\right)\right]^{2}-K_{i}
$$

Differentiating and solving for $t^{i d}$ yields:

$$
t^{i d}=\frac{\lambda e_{i}^{2}-1}{e_{i}\left(1+\lambda e_{i}^{2}\right)}
$$

The tax rate is positive if and only if:

$$
\lambda e_{i}^{2}>1
$$

Substituting (17) into (6), we find the equilibrium output level $q_{i}^{i d}$ and the output 
level $q_{0}^{i d}$ that the downstream firm would choose using its own abatement technology:

$$
q_{i}^{i d}=\frac{1}{\lambda e_{i}^{2}+1}, \quad \quad q_{d}^{i d}=\frac{\lambda e_{i}^{3}-\lambda e_{i}^{2}+e_{i}+1}{2 e_{i}\left(\lambda e_{i}^{2}+1\right)}
$$

Substituting this and (7) into (10), we obtain the technology fee as:

$$
F_{h}^{i d}=\tilde{\alpha}\left(\left[\frac{1}{\lambda e_{i}^{2}+1}\right]^{2}-\left[\frac{\lambda e_{i}^{3}-\lambda e_{i}^{2}+e_{i}+1}{2 e_{i}\left(\lambda e_{i}^{2}+1\right)}\right]^{2}+K_{d}\right)+(1-\tilde{\alpha}) K_{1}
$$

\subsection{Free Trade}

\subsubsection{Domestic firm has found the new technology}

In scenarios $n g, g=f, n$, the domestic upstream firm supplies the technology. ${ }^{11}$ Substituting $e_{1}=e_{n}, e_{2}=e_{k}$ and $\Pi^{n g}+F_{h}^{n g}=\pi_{n}^{n g}$ by (11), along with (6) and (7) into (15), social welfare in scenario $n g$ is:

$$
W^{n g}=\left[\frac{1-t e_{n}}{2}\right]^{2}+\frac{1}{2}\left[\frac{1-t e_{n}}{2}\right]^{2}+t e_{n}\left(\frac{1-t e_{n}}{2}\right)-\frac{1}{2} \lambda\left[e_{n}\left(\frac{1-t e_{n}}{2}\right)\right]^{2}-K_{n}
$$

Differentiating and solving for $t^{n g}$ yields:

$$
t^{n f}=t^{n n}=\frac{\lambda e_{n}^{2}-1}{e_{n}\left(\lambda e_{n}^{2}+1\right)}
$$

Substituting this into (6), we obtain the equilibrium outputs as:

$$
q_{n}^{n f}=q_{n}^{n n}=\frac{1}{\lambda e_{n}^{2}+1}
$$

For scenario $n f$, substituting (22) into (6), we find the equilibrium output of the downstream firm when it uses the less efficient technology $f$ :

$$
q_{f}^{n f}=\frac{\lambda e_{n}^{3}-e_{f} \lambda e_{n}^{2}+e_{n}+e_{f}}{2 e_{n}\left(\lambda e_{n}^{2}+1\right)}
$$

Substituting (7), (23) and (24) into (10), the domestic eco-firm's licence fee is:

$$
F_{h}^{n f}=\left[\frac{1}{\lambda e_{n}^{2}+1}\right]^{2}-\left[\frac{\lambda e_{n}^{3}-e_{f} \lambda e_{n}^{2}+e_{n}+e_{f}}{2 e_{n}\left(\lambda e_{n}^{2}+1\right)}\right]^{2}+K_{f}
$$

For scenario $n n$, we have $F_{h}^{n n}=K_{n}$.

\footnotetext{
${ }^{11}$ In fact, in scenario $n n$, the upstream firms compete the fee down to $K_{n}$ and the downstream firm as well as the government are indifferent between the two suppliers. For expositional simplicity, we let the domestic firm supply the technology.
} 


\subsubsection{Domestic firm has not found the new technology}

In scenarios $j h, j=f, n$, the foreign firm supplies the technology to the downstream firm. Substituting $e_{1}=e_{j}, e_{2}=e_{h}, F_{h}^{j h}=0$ and $\Pi^{j h}=\pi_{h}^{j h}$ (by (11)) along with (6) and (7) into (15), social welfare in scenario $j h$ is:

$$
W^{j h}=\left[\frac{1-t e_{h}}{2}\right]^{2}+\frac{1}{2}\left[\frac{1-t e_{j}}{2}\right]^{2}+t e_{j}\left(\frac{1-t e_{j}}{2}\right)-\frac{1}{2} \lambda\left[e_{j}\left(\frac{1-t e_{j}}{2}\right)\right]^{2}
$$

Differentiating and solving for $t^{j h}$ yields:

$$
t^{j h}=\frac{\lambda e_{j}^{3}+e_{j}-2 e_{h}}{\lambda e_{j}^{4}+3 e_{j}^{2}-2 e_{h}^{2}}
$$

The denominator on the RHS is positive, because it is the second order condition for welfare maximization. Thus $t^{j h}>0$ holds in the welfare optimum if and only if:

$$
\lambda e_{j}^{3}+e_{j}-2 e_{h}>0
$$

Substituting (27) into (6), we obtain the equilibrium output level $q_{j}^{j h}$ and the output level $q_{h}^{j h}$ with the less efficient techonology $h$ :

$$
q_{j}^{j h}=\frac{e_{j}^{2}+e_{j} e_{h}-e_{h}^{2}}{\lambda e_{j}^{4}+3 e_{j}^{2}-2 e_{h}^{2}}, \quad \quad q_{h}^{j h}=\frac{e_{j}\left(3 e_{j}-e_{h}+\lambda e_{j}^{3}-\lambda e_{j}^{2} e_{h}\right)}{2\left(\lambda e_{j}^{4}+3 e_{j}^{2}-2 e_{h}^{2}\right)}
$$

Substituting this and (7) into (10), we find the foreign firm's technology fee:

$$
F_{f}^{j h}=\left[\frac{e_{j}^{2}+e_{j} e_{h}-e_{h}^{2}}{\lambda e_{j}^{4}+3 e_{j}^{2}-2 e_{h}^{2}}\right]^{2}-\left[\frac{e_{j}\left(3 e_{j}-e_{h}+e_{j}^{3} \lambda-\lambda e_{j}^{2} e_{h}\right)}{2\left(\lambda e_{j}^{4}+3 e_{j}^{2}-2 e_{h}^{2}\right)}\right]^{2}+K_{h}
$$

\section{$6 \quad$ R\&D decisions}

In this section we solve for stage one of the game under autarky (subsection 6.1) and free trade (subsection 6.2) and we compare the domestic firm's R\&D incentives under both regimes (subsection 6.3).

\subsection{Autarky}

In autarky, the domestic firm will undertake $R \& D$ if its expected payoff from undertaking $R \& D$ exceeds its payoff from not doing $R \& D$ :

$$
p^{h} R_{h}^{n d}+\left(1-p^{h}\right) R_{h}^{h d}-C^{h}>R_{h}^{h d}
$$


Table 1: Payoff matrix for the domestic and foreign firms' $\mathrm{R}$ and $\mathrm{D}$ decisions

\begin{tabular}{|l|l|l|}
\hline Home/Foreign & R\&D & No R\&D \\
\hline R\&D & $\begin{array}{l}p^{h}\left(1-p^{f}\right) R_{h}^{n f}-C^{h} ; \\
\left(1-p^{h}\right)\left(1-p^{f}\right)\left(R_{f}^{f h}+R_{f}\right)+\left(1-p^{h}\right) p^{f}\left(R_{f}^{n h}+R_{n}\right)-C^{f}\end{array}$ & $\begin{array}{l}p^{h} R_{h}^{n f}-C^{h} ; \\
\left(1-p^{h}\right)\left(R_{f}^{f h}+R_{f}\right)\end{array}$ \\
\hline No R\&D & $0 ; p^{f}\left(R_{f}^{n h}+R_{n}\right)+\left(1-p^{f}\right)\left(R_{f}^{f h}+R_{f}\right)-C^{f}$ & $0 ; R_{f}^{f h}+R_{f}$ \\
\hline
\end{tabular}

Note: $R^{s}$ given by $(12) ; F_{h}^{n f}$ given by $(25) ; F_{f}^{f h}, F_{f}^{n h}$ given by (30) with $j=f, n$.

with $R^{s}$ given by (12) and $F_{h}^{i d}, i=n, h$, given by (20). Thus the firm will do R\&D if and only if: ${ }^{12}$

$$
C^{h}<C_{A}^{h} \equiv p^{h}\left(R_{h}^{n d}-R_{h}^{h d}\right)
$$

\subsection{Free trade}

Table 1 shows the payoff matrix for the domestic and foreign upstream firms in stage one, depending on either firm's decision whether or not to do R\&D. The first (second) term in each cell shows the payoff to the domestic (foreign) firm.

Let us first look at the foreign firm's incentive to do R\&D. In case the domestic firm does R\&D, the foreign firm will undertake R\&D when:

$$
C^{f}<C_{2}^{f} \equiv\left(1-p^{h}\right) p^{f}\left(R_{f}^{n h}+R_{n}-R_{f}^{f h}-R_{f}\right)
$$

In case the domestic firm does not do R\&D, the foreign firm will do R\&D when:

$$
C^{f}<C_{1}^{f} \equiv p^{f}\left(R_{f}^{n h}+R_{n}-R_{f}^{f h}-R_{f}\right)
$$

It is easily seen from (32) and (33) that when the domestic firm does R\&D, the critical R\&D cost level for the foreign firm is lower:

$$
C_{2}^{f}<C_{1}^{f}
$$

The reason for this is that without domestic $R \& D$, the foreign firm can always increase its net revenues from $R_{f}^{f h}+R_{f}$ to $R_{f}^{n h}+R_{n}$ if it finds the new technology. With domestic R\&D, the foreign firm can only make this increase if the domestic firm

\footnotetext{
${ }^{12} C_{A}^{h}$ in (31), $C_{2}^{f}$ in (32), $C_{1}^{f}$ in (33), $C_{2}^{h}$ in (35) and $C_{1}^{h}$ in (36) are all positive by (14) and $R_{n}>R_{f}$.
} 
does not find the new technology. In case the domestic firm finds the new technology, the foreign firm does not earn any revenues, whether it is successful itself (then the fee is competed down to $K_{n}$ ) or not (then the domestic firm's technology is better).

Now we turn to the domestic upstream firm's incentive to do R\&D. If the foreign firm does R\&D, the domestic firm will undertake $\mathrm{R} \& \mathrm{D}$ when $C^{h}<C_{2}^{h}$ or from (3):

$$
C^{f}<\phi C_{2}^{h}, \quad C_{2}^{h} \equiv \phi p^{h}\left(1-p^{f}\right) R_{h}^{n f}
$$

In case the foreign firm does not do $R \& D$, the domestic firm undertakes $R \& D$ for $C^{h}<C_{1}^{h}$ or from (3):

$$
C^{f}<\phi C_{1}^{h}, \quad C_{1}^{h} \equiv \phi p^{h} R_{h}^{n f}
$$

It is easily seen from (35) and (36) that for the domestic firm as well, its critical $R \& D$ cost level is lower if the rival firm does R\&D:

$$
C_{2}^{h}<C_{1}^{h}
$$

The reason is analogous to the reason behind inequality (34).

There will be an (R\&D, No R\&D) equilibrium if $C_{2}^{f}<C^{f}<\phi C_{1}^{h}$ and a (No $\mathrm{R} \& \mathrm{D}, \mathrm{R} \& \mathrm{D})$ equilibrium if $\phi C_{2}^{h}<C^{f}<C_{1}^{f}$. In order to avoid the indeterminacy and complication of multiple equilibria, we have to assume either $C_{2}^{f}>\phi C_{1}^{h}$ or $\phi C_{2}^{h}>C_{1}^{f}$. We shall assume the former, because the conditions for it to hold are less stringent:

$$
\left(1-p^{h}\right) p^{f}\left(R_{f}^{n h}+R_{n}-R_{f}^{f h}-R_{f}\right)>\phi p^{h} R_{h}^{n f}
$$

This inequality requires relatively few extra constraints, because $p^{f} \geq p^{h}, \phi \leq 1$ and $R_{n}>R_{f}$. On the other hand, it is ambiguous whether $R_{f}^{n h}-R_{f}^{f h}$ is larger or smaller than $R_{h}^{n f}$.

From (34), (37) and (38), we then have the following inequalities:

$$
\phi C_{2}^{h}<\phi C_{1}^{h}<C_{2}^{f}<C_{1}^{f}
$$

The Nash equilibrium is then (R\&D, R\&D) if $C^{f}<\phi C_{2}^{h}$, (No R\&D, R\&D) if $\phi C_{2}^{h}<C^{f}<C_{1}^{f}$, and (No R\&D, No R\&D) if $C^{f}>C_{1}^{f}$. 


\subsection{Domestic firm's R\&D incentive}

The domestic firm will do R\&D in autarky if and only if $C^{h}<C_{A}^{h}$ in (31) and with free trade if and only if $C^{h}<C_{2}^{h}$ in (35). We see that free trade gives the domestic firm a larger incentive to invest in R\&D if and only if: ${ }^{13}$

$$
\left(1-p^{f}\right) R_{h}^{n f}>R_{h}^{n d}-R_{h}^{h d}
$$

The inequality is more likely to hold for:

- Low $\tilde{\alpha}$ : By (12) and (20), the lower the domestic upstream firm's bargaining power $\tilde{\alpha}$ vis-a-vis the downstream firm in autarky, the lower its fees and the lower the increase in its fee from finding the new technology in autarky.

- Low $e_{h}$, because $R_{h}^{h d}$ is decreasing in $e_{h}$ by (12) and (14): The better the domestic firm's existing technology, the higher the fee it will obtain for $e_{h}$ in autarky and therefore the lower the $\mathrm{R} \& \mathrm{D}$ incentive under autarky.

- Low $p^{f}$ : The lower $p^{f}$, the higher the probability that the foreign firm fails to find the new technology, allowing the domestic firm to earn positive net revenue from the new technology (if it finds it) under free trade.

- High $e_{f}$, because by (12) and (25), $R_{h}^{n f}$ is increasing in $e_{f}$ : The worse the foreign firm's existing technology, the higher the licence fee the domestic firm can obtain if it finds the new technology and the foreign firm does not, and therefore the higher the domestic firm's R\&D incentive under free trade.

Not only can $C_{A}^{h}$ be above or below $C_{2}^{h}$, it can also be above or below $C_{1}^{f} / \phi$, with $C_{1}^{f}$ given by (33) and $\phi$ by (3). This means that any combination of the two possible outcomes under autarky and the three outcomes under free trade can arise.

\footnotetext{
${ }^{13}$ Trade liberalization which opens up the domestic market to the foreign upstream firm, always increases the foreign firm's R\&D incentive, because its net revenue from licensing to the domestic downstream firm is higher (or at least equally high) with the new technology.
} 


\section{Comparing autarky and free trade}

In this section, we compare the autarky and free trade equilibria with respect to expected welfare and expected environmental damage. For welfare, we find: ${ }^{14}$

Proposition 1 Expected welfare is higher with free trade than in autarky for any combination of equilibria, except when the domestic upstream firm undertakes RED in autarky and:

1. neither firm undertakes RESD with free trade. In this case, expected welfare is higher with free trade if and only if the domestic upstream firm's success probability $p^{h}$ of R\&DD satisfies:

$$
p^{h}<\frac{W^{f h}-W^{h d}+C^{h}}{W^{n d}-W^{h d}}
$$

2. only the foreign firm undertakes REDD with free trade. In this case, expected welfare is higher with free trade if:

$$
E^{n h}>E^{n d}
$$

We see that the domestic country is better off with free trade in almost all equilibria where trade liberalization makes cleaner technologies available (or raises the probability of acquiring cleaner technologies). This is true even though the fee for using these cleaner technogies may well have to be paid to the foreign upstream firm. The reason is that the fee equals the domestic downstream firm's change in profits, which is sufficiently close to the change in welfare for the whole economy.

Turning to environmental damage, we find:

\footnotetext{
${ }^{14}$ The proofs of Propositions 1 and 2 are in Appendix C.
} 
Proposition 2 Expected environmental damage is higher with free trade than in autarky for any combination of equilibria, except when the domestic upstream firm undertakes RED in autarky and:

1. neither firm undertakes RESD with free trade. In this case, expected environmental damage is higher with free trade if and only if the domestic upstream firm's success probability $p^{h}$ of RED satisfies:

$$
p^{h}<\frac{\left(E^{f h}\right)^{2}-\left(E^{h d}\right)^{2}}{\left(E^{n d}\right)^{2}-\left(E^{h d}\right)^{2}}
$$

2. only the foreign firm undertakes RESD with free trade. In this case, expected welfare is higher with free trade if and only if the domestic upstream firm's cost $C^{h}$ of RED satisfies:

$$
C^{h}>p^{h}\left(W^{n d}-W^{n h}\right)-\left(1-p^{f}\right)\left(W^{f h}-W^{h d}\right)-\left(p^{f}-p^{h}\right)\left(W^{n h}-W^{h d}\right)
$$

Paradoxically, in almost all equilibria where trade liberalization leads to a cleaner technology becoming available (or raises the probability of acquiring cleaner technologies), expected environmental damage is unambiguously higher under free trade. This is because the government takes this opportunity of cleaner production to increase welfare at the expense of the environment by reducing the effective tax rate $t e_{1}$ on output, prompting the firm to produce more and ultimately even to pollute more.

The result is similar to the rebound (Khazzoom, 1980) and backfire effects (Saunders, 2000) in energy economics, where the introduction of a more energy-efficient technology (e.g. a more economical car engine) leads to an increase in demand which partly (rebound) or more than completely (backfire) offsets the potential energy saving. Empirically, the rebound effect is generally between 5 and 50\% (Binswanger, 2001), but Hanley et al. (2009) find that an energy efficiency improvement in Scotland ultimately backfires. In the same vein, Fisher-Vanden and Ho (2010) predict that a takeoff of the science and technology sector in China will result in cleaner technologies becoming available, but it will increase energy use and $\mathrm{CO}_{2}$ emissions because of an increase in overall production and a shift to more energy-intensive sectors. 
Our model could be said to demonstrate a political backfire effect, because the availability of a cleaner technology triggers a change in environmental policy, ultimately resulting in more pollution.

\section{Conclusion}

In this paper we have analyzed the effects of trade liberalization in environmental goods and services (EGS) on a country's domestic eco-firm, on welfare and on pollution. Whereas other papers on this subject have assumed that the abatement technology is end-of-pipe, we assume integrated technologies that reduce the emissions-to-output ratio of production.

We have seen that the effect of trade liberalization on the domestic eco-firm's R\&D incentive is ambiguous. The R\&D incentive increases with trade if the domestic firm's existing technology is relatively clean, its bargaining power in autarky is low (so that its R\&D incentive under autarky is low), the foreign eco-firm's existing technology is not too clean and its probability of finding the new technology is low (so that the domestic firm's R\&D incentive with trade is high). If the domestic firm does R\&D under autarky but not with trade, liberalization may decrease welfare. Thus it may be best for a developing country to first liberalize trade in environmental goods with similar countries whose environmental technologies are not too much better than its own. This will stimulate R\&D by its domestic eco-industry, increasing welfare and putting the sector in a better position to face competition from more advanced ecofirms at a later date.

We further see that, although trade liberalization means that cleaner technologies become available, it generally leads to an increase in pollution. This is because the government takes the opportunity to increase welfare by reducing the effective tax on polluting output, boosting the downstream firm's profits and consumer surplus while increasing pollution. While the WTO argues that trade liberalization in EGS will benefit the environment as well as the consumer, our model sees the consumers benefit at the expense of the environment. This casts doubt on one of the main motivations for trade liberalization in EGS. 
If the eco-industry invented a technology that was much cleaner than the existing technologies, pollution would decline. However, the eco-industry does not have any incentive to undertake $R \& D$ into a very clean technology, or even to market it if it is available. This is because when a very clean technology is available, pollution is not a pressing problem anymore and the government will set a negative environmental tax rate to stimulate production. Then the eco-industry would not be able to make any money from its invention.

The problem of negative tax rates is particularly severe in our model, because we have assumed for simplicity that there is just one polluting firm which would like to produce much less than the welfare-maximizing amount. If the industry were more competitive, there would be less need for negative taxes and more incentive for $\mathrm{R} \& \mathrm{D}$ into cleaner technologies. However, for very clean technologies, the tax rate and the licence fee would still be decreasing in the cleanliness of the technology, discouraging R\&D into such cleaner technologies.

We find that welfare usually increases with trade liberalization and generally changes in the same direction as pollution. If trade liberalization increases pollution as well as welfare, one might argue that the increase in pollution is nothing to worry about, because environmental damage is just an element of social welfare, which is increasing overall. However, particularly in developing countries, governments might not value the environment enough and the increase in pollution might reduce welfare, especially in the longer run.

Finally, let us reflect on the significance of our assumptions on policy timing, tariff revenues and environmental policy instruments.

We have assumed that the domestic government cannot commit to its environmental policy before the eco-firms make their innovation decision. While one may question whether governments, especially of developing countries, can commit to a policy that is not ex post optimal, let us here explore the commitment scenario. If the government could only commit to a single tax rate, regardless of the eco-firms' R\&D decisions and success, welfare would be lower than in the no-commitment scenario if the firms undertake $\mathrm{R} \& \mathrm{D}$ and the new technology is much cleaner than the existing ones. If 
the government could commit to different tax rates depending on which technologies are available, it would always be able to replicate the no-commitment policies and outcome. The only improvement that commitment can make is on the eco-firms' R\&D decision. The government can now adjust the emission tax rate to increase the firms' R\&D incentive. It will only find this worthwhile if $R \& D$ costs are just below the level where the eco-firms would do R\&D in the no-commitment scenario. For relatively low and relatively high $\mathrm{R} \& \mathrm{D}$ costs however, the government would not adjust the no-commitment policy, and our analysis carries over to the commitment scenario.

We have assumed that pre-liberalization, tariff and/or non-tariff barriers are so high that the foreign eco-firm will not offer its technology on the domestic market. However, it could also be possible that the foreign firm is offering its technology in spite of these barriers, and that the domestic government earns tariff revenue from this. The tariff then allows the domestic government to capture some of the foreign eco-firm's rents and may be an important source of government revenue. Indeed, developing countries are concerned about the loss of tariff revenue from liberalizing trade in environmental goods and services (UNEP, ITC and ICTSD, 2012). We will leave the issue of tariff revenue for future research.

We have assumed that environmental policy consists of an emission tax. However, environmental policy around the world mainly consists of direct regulation or command-and-control. The effects of a relative standard, imposing a maximum emissionto-output ratio, are straightforward. The downstream firm will only be interested in technologies that meet the standard, selecting from these the technology with the lowest equipment cost. An absolute standard, limiting emissions to a certain fixed amount, requires more analysis. We will also leave this for future research. 


\section{A Appendix A: Conditions for $q_{2}^{s}>0$}

Autarky. $q_{d}^{i d}$ in (19) is decreasing in $\lambda$ and has an interior minimum in $e_{i} \in[1 / \sqrt{\lambda} ; 1]$ given $\lambda$. To make sure that $q_{d}^{i d}>0$ for all $e_{i} \in[1 / \sqrt{\lambda} ; 1]$, we calculate the $\lambda$ where the minimum equals zero. Setting $q_{d}^{i d}=0$ and $d q_{d}^{i d} / d e_{i}=0$ in (19) yields, respectively:

$$
\begin{gathered}
\frac{\lambda e_{i}^{3}-\lambda e_{i}^{2}+e_{i}+1}{e_{i}\left(\lambda e_{i}^{2}+1\right)}=0 \\
-\lambda^{2} e_{i}^{4}+4 \lambda e_{i}^{2}+1=0
\end{gathered}
$$

The only positive solution for $\lambda$ and $e_{i}$ is $\lambda=\frac{5}{2} \sqrt{5}+\frac{11}{2}$. Therefore $q_{d}^{i d}>0$ for all $e_{i} \in[1 / \sqrt{\lambda} ; 1]$ if and only if:

$$
\lambda<\frac{5}{2} \sqrt{5}+\frac{11}{2} \approx 11.09
$$

Free trade. Comparing (19) and (24), we see that $q_{f}^{n f}>q_{d}^{n d}$ by (18). Thus, condition (A1) that ensures $q_{d}^{n d}>0$ is also sufficient for $q_{f}^{n f}>0$.

Output $q_{h}^{j h}, j=f, n$, in (29) is positive for all values of $e_{j}$ for which the second order condition holds (which implies that the denominator on the RHS of (29) is positive) if and only if:

$$
\lim _{e_{j} \downarrow \hat{e}_{j}} \frac{e_{j}\left(3 e_{j}-e_{h}+e_{j}^{3} \lambda-\lambda e_{j}^{2} e_{h}\right)}{2\left(\lambda e_{j}^{4}+3 e_{j}^{2}-2 e_{h}^{2}\right)}=+\infty
$$

where $\hat{e}_{j}$ as a function of $e_{h}$ and $\lambda$ is implicitly defined by:

$$
\lambda e_{j}^{4}+3 e_{j}^{2}-2 e_{h}^{2}=0
$$

The point where the LHS of (A2) switches from $+\infty$ to $-\infty$ is where

$$
3 e_{j}-e_{h}+e_{j}^{3} \lambda-\lambda e_{j}^{2} e_{h}=0
$$

and (A3) holds. Solving (A3) and (A4) simultaneously for $\lambda$ and $e_{j}$, we find that the only positive real solution features $\lambda=\frac{1}{2 e_{h}^{2}}(3 \sqrt{5}+5)$. Then $q_{h}^{j h}>0$ for all $e_{j}$ if and only if:

$$
\lambda<\frac{3 \sqrt{5}+5}{2 e_{h}^{2}} \approx \frac{5.8541}{e_{h}^{2}}
$$




\section{B Appendix B: The licence fee}

In Section 4, we introduced the restriction that the licence fee should be decreasing in $e_{1}$. In this appendix, we discuss the conditions under which this is the case. ${ }^{15}$

Figure 1. The domestic firm's licence fee $F_{h}^{i d}$ under autarky for $\tilde{\alpha}=1$ when the domestic firm has technology $e_{i}, i=h, n$.

\section{B.1 Autarky}

Figure 1 shows the licence fee $F_{h}^{i d}$ (given by (20)) as a function of $e_{i}$ for different values of $\lambda$ with $\tilde{\alpha}=1$. The condition $d F_{h}^{i d} / d e_{i}<0$ is binding for $i=n$, because it is clear from Figure 1 that when $d F_{h}^{n d} / d e_{n}<0$, then $d F_{h}^{h d} / d e_{h}<0$ as well, since $e_{h}>e_{n}$. Thus $e_{n}$ should exceed $\bar{e}_{n}$, where $\bar{e}_{n}$ is defined implicitly by:

$$
d F_{h}^{n d}\left(\bar{e}_{n}\right) / d e_{n}=0
$$

\section{B.2 Free trade}

Domestic firm has found the new technology. Comparing $d F_{h}^{n f} / d e_{n}$ in (25) to $d F_{h}^{n d} / d e_{n}$ in (20) with $i=n$, we see that qualitatively the only difference lies in the less efficient technology 2 which has $e_{f}<1$ in scenario $n f$ and $e=1$ in $n d$. At $\bar{e}_{n}$ as defined by (B1) we must have $d t^{n d} / d e_{n}>0$ by (13). Then since emissions with the less efficient technology $E_{2}$ are lower in scenario $n f$ than in $n d, d F_{h}^{n f}\left(\bar{e}_{n}\right) / d e_{n}<0$ and $d F_{h}^{n f} / d e_{n}=0$ occurs at an $e_{n}<\bar{e}_{n}$.

Domestic firm has not found the new technology. It can be shown that $F_{f}^{j h}$ in $(30), j=n, f$, is first increasing and then decreasing in $e_{j}$. Then the condition $d F_{f}^{j h} / d e_{j}<$ 0 is binding for $j=n$, since when $d F_{f}^{n h} / d e_{n}<0$, then $d F_{h}^{f h} / d e_{f}<0$ as well, since $e_{f}>e_{n}$. Thus $e_{n}$ should exceed $\tilde{e}_{n}$, where $\tilde{e}_{n}$ is defined implicitly by:

$$
d F_{f}^{n h}\left(\tilde{e}_{n}, e_{h}\right) / d e_{n}=0
$$

It can be shown that $\tilde{e}_{n}\left(e_{h}\right)$ is an increasing function of $e_{h}$.

\footnotetext{
${ }^{15}$ Further details are available from the corresponding author upon request.
} 
Table 2: Minimum values of $e_{n}$ from (11)

\begin{tabular}{rll}
$\lambda$ & {$\left[\bar{e}_{n}, \tilde{e}_{n}\left(\bar{e}_{n}\right)\right]$} & {$\left[\tilde{e}_{n}\left(e_{h}^{\max }\right), e_{h}^{\max }\right]$} \\
\hline 3 & {$[0.708 ; 0.779]$} & {$[0.807 ; 1]$} \\
5 & {$[0.570 ; 0.644]$} & {$[0.673 ; 1]$} \\
7 & {$[0.485 ; 0.551]$} & {$[0.565 ; 0.914]$} \\
9 & {$[0.426 ; 0.483]$} & {$[0.498 ; 0.807]$} \\
11 & {$[0.383 ; 0.432]$} & {$[0.451 ; 0.730]$} \\
\hline
\end{tabular}

Note: $\bar{e}_{n}$ defined by (B1), $\tilde{e}_{n}$ by (B2).

\section{B.3 Conclusion}

We have found two minimum values of $e_{n}: \bar{e}_{n}$ in (B1) does not depend on $e_{h}$, while $\tilde{e}_{n}$ in (B2) is increasing in $e_{h}$. This means that for low values of $e_{h}$, the binding constraint is $e_{n}>\bar{e}_{n}$, while for higher values of $e_{h}$ it is $e_{n}>\tilde{e}_{n}$. Table 2 shows how the minimum $e_{n}$ value changes with $e_{h}$ for selected values of $\lambda$. With $\lambda=3$, for instance, $\bar{e}_{n}=0.708$ while $\tilde{e}_{n}=0.708$ for $e_{h}=0.779$. Thus for $0.708<e_{h}<0.779$, the binding constraint is $e_{n}>\bar{e}_{n}=0.708$. For $e_{h}>0.779$, the binding constraint is $e_{n}>\tilde{e}_{n}$, with $\tilde{e}_{n}$ increasing in $e_{h}$. For the maximum value of one for $e_{h}, \tilde{e}_{n}=0.807$. For the $\lambda$ values of 3 and 5 , the maximum value of $e_{h}$ is one, whereas for higher $\lambda$ 's it is constrained by (A5).

\section{Appendix C: Proofs}

\section{C.1 Proof of Proposition 1}

Let us first collect the expressions for welfare. Substituting (17) and (19) into (16) yields welfare in scenario $i d, i=h, n$ :

$$
W^{i d}=\frac{1}{2\left(\lambda e_{i}^{2}+1\right)}-K_{i}
$$

Substituting (22) and (23) into (21) gives welfare in scenarios $n n$ and $n f$ as:

$$
W^{n n}=W^{n f}=\frac{1}{2\left(\lambda e_{n}^{2}+1\right)}-K_{n}
$$

Substituting (27) and (29) into (26) gives welfare in scenario $j h, j=f, n$, as:

$$
W^{j h}=\frac{\lambda e_{j}^{4}-2 \lambda e_{h} e_{j}^{3}+\lambda e_{h}^{2} e_{j}^{2}+5 e_{j}^{2}-2 e_{h} e_{j}-e_{h}^{2}}{4\left(\lambda e_{j}^{4}+3 e_{j}^{2}-2 e_{h}^{2}\right)}-K_{h}
$$

Before proving the Proposition, we first establish the following two lemmas: 
Lemma 1 When the domestic firm has not found the new technology, welfare is higher with free trade than under autarky: $W^{j h}>W^{h d}$ with $j=f, n$.

Proof. From (C1) with $i=h$ and (C3), it is clear that $W^{h d}=W^{j h}$ for $e_{j}=e_{h}$. From (C3):

$$
\frac{d W^{j h}}{d e_{j}}=\frac{-7 e_{j} e_{h}^{2}+2 e_{j}^{3}+3 e_{j}^{2} e_{h}-2 \lambda e_{j}^{5}-2 \lambda e_{j} e_{h}^{4}+6 \lambda e_{j}^{2} e_{h}^{3}-2 \lambda e_{j}^{3} e_{h}^{2}+\lambda^{2} e_{j}^{6} e_{h}-\lambda^{2} e_{j}^{5} e_{h}^{2}}{2\left(3 e_{j}^{2}-2 e_{h}^{2}+\lambda e_{j}^{4}\right)^{2}}
$$

The sign of $d W^{j h} / d e_{j}$ in (C4) is the sign of the numerator on the RHS. Defining $a \equiv e_{j} / e_{h}, b \equiv \lambda e_{j}^{2}$, the sign of the numerator is the sign of:

$$
\Phi=-7 a^{2}+2 a^{4}+3 a^{3}-2 b a^{4}-2 b+6 b a-2 b a^{2}+b^{2} a^{3}-b^{2} a^{2}
$$

$\Phi$ has a maximum in $b$ for:

$$
b=b^{*} \equiv \frac{3 a-a^{3}-a^{2}-1}{a^{2}(1-a)}
$$

$b^{*}$ is positive for $a \in(\bar{a} ; 1]$, with $\bar{a} \approx 0.414$. For $a \in[0 ; \bar{a}], \Phi$ reaches its maximum at $b=0$, which from (C5) is clearly negative.

Substituting $b=b^{*}$ from (C6) into (C5), we find the maximum possible value of $\Phi$ given $a \in(0.414 ; 1]$ :

$$
\Phi^{*}=\frac{1-4 a^{4}+6 a^{2}-5 a}{a^{2}}
$$

Plotting this expression shows that $\Phi^{*}<0$ for all $a \in(0.414 ; 1]$. Thus $\Phi<0$ in (C5) for all feasible values of $a$ and $b$, which means that $d W^{j h} / d e_{j}<0$ in (C4). This combined with $W^{h d}=W^{j h}$ for $e_{j}=e_{h}$ proves the lemma.

Lemma 2 In scenario $n f$ with free trade, welfare $W^{n f}$ net of the domestic upstream firm's net revenue $R_{h}^{n f}$ exceeds welfare $W^{\text {hd }}$ in scenario hd under autarky: $W^{n f}-R_{h}^{n f}>$ $W^{h d}$.

Proof. From (C2) and (25):

$$
W^{n f}-R_{h}^{n f}=\frac{1}{2} \frac{\lambda e_{n}^{2}-1}{\left(\lambda e_{n}^{2}+1\right)^{2}}+\frac{\left(\lambda e_{n}^{3}-\lambda e_{f} e_{n}^{2}+e_{n}+e_{f}\right)^{2}}{4 e_{n}^{2}\left(\lambda e_{n}^{2}+1\right)^{2}}-K_{n}
$$

Differentiating $(\mathrm{C} 7)$ with respect to $e_{n}$, we obtain:

$$
\frac{d\left(W^{n f}-R_{h}^{n f}\right)}{d e_{n}}=\frac{\Omega}{2 e_{n}^{3}\left(\lambda e_{n}^{2}+1\right)^{3}}
$$


with

$$
\Omega \equiv 2 a^{2} b(3-b)+a(b+1)\left(b^{2}-4 b-1\right)-(b-1)\left(b^{2}-4 b-1\right)
$$

where $a \equiv e_{n} / e_{f}, b \equiv \lambda e_{n}^{2}$. Note that $b<\frac{5}{2}+\frac{3}{2} \sqrt{5}$ by (A5).

The sign of the RHS of (C8) is the sign of $\Omega$ which is quadratic in $a$ with a maximum (minimum) for $b>(<) 3$. The highest value of $\Omega$ is then at $\partial \Omega / \partial a=0$ for $b>3$ (if this is an internal maximum) and at either the highest or lowest value of $a$ for $b \leq 3$. The highest value of $a$ is 1 , for which $\Omega=-2(b+1)<0$. The lowest value for $a$ is where $d F_{h}^{n f} / d e_{n}=0$ from (25). Substituting this into (C9), we find $\Omega=-2 a^{2} b(b+1)<0$. For $b>3$, the maximum value of $\Omega$ in (C9) occurs at:

$$
a=a^{*} \equiv \frac{(b+1)\left(b^{2}-4 b-1\right)}{4 b(b-3)}
$$

Substituting this into (C9), the highest possible value of $\Omega$ is:

$$
\Omega^{*}=\left(b^{2}-4 b-1\right)\left(b^{4}-10 b^{3}+24 b^{2}-30 b-1\right)
$$

We see that $a^{*}>0$ and $\Omega^{*}<0$ for $b \in(3 ; 2+\sqrt{5})$ and $a^{*}<0$ and $\Omega^{*}>0$ for $b \in\left(2+\sqrt{5} ; \frac{5}{2}+\frac{3}{2} \sqrt{5}\right)$. Thus, for all values of $b$ for which there is potentially an interior maximum $\left(a^{*}>0\right), \Omega^{*}$ is negative. We conclude that $\Omega$ is negative so that the RHS of (C8) is negative. The lowest possible value of $\left(W^{n f}-F_{h}^{n f}\right)$ is thus achieved at the maximum value of $e_{n}$, which is $e_{f}$. Setting $e_{n}=e_{f}$ in $(\mathrm{C} 7)$, we find from $(\mathrm{C} 1)$ :

$$
W^{n f}-R_{h}^{n f} \geq \frac{1}{2\left(\lambda e_{f}^{2}+1\right)}-K_{n}>\frac{1}{2\left(\lambda e_{h}^{2}+1\right)}-K_{h}=W^{h 0}
$$

The inequality follows from (4) and $e_{f}<e_{h}$.

We will now prove Proposition 1 by examining each possible combination of R\&D decisions in turn. ${ }^{16}$

\section{C.1.1 No R\&D in autarky; (No R\&D, No R\&D) with trade}

In autarky, welfare is $W^{h d}$. With trade, welfare is $W^{f h}$. By Lemma $1, W^{f h}>W^{h d}$.

\section{C.1.2 No R\&D in autarky; (No R\&D, R\&D) with trade}

In autarky, welfare is $W^{h d}$. With trade, welfare is $W^{n h}$ if the foreign firm's $\mathrm{R} \& \mathrm{D}$ is successful and $W^{f h}$ if it is not. By Lemma $1, W^{j h}>W^{h d}, j=n, f$.

\footnotetext{
${ }^{16}$ The expressions for welfare are $(\mathrm{C} 1),(\mathrm{C} 2)$ and $(\mathrm{C} 3)$. To avoid repetition, we will omit references to these equations in the following analysis.
} 


\section{C.1.3 No R\&D in autarky; (R\&D, R\&D) with trade}

In autarky, welfare is $W^{h d}$. With trade, welfare is $W^{n n}-C^{h}=W^{n f}-C^{h}$ if the domestic firm's R\&D is successful and $W^{j h}-R, j=f, n$, if it is not. Thus we have: ${ }^{17}$

$$
\begin{aligned}
W^{R R}-W^{N} & =p^{h} W^{n f}+\left(1-p^{h}\right) W^{j h}-W^{h d}-C^{h}> \\
& >p^{h}\left(W^{n f}-R_{h}^{n f}-W^{h d}\right)+\left(1-p^{h}\right)\left[W^{j h}-W^{h d}\right]>0
\end{aligned}
$$

The first inequality follows from $C^{h}<C_{2}^{h}$ in (R\&D, R\&D), with $C_{2}^{h}$ given by (36). The second inequality follows from Lemmas 1 and 2 .

\section{C.1.4 R\&D in autarky; (No R\&D, No R\&D) with trade}

In autarky, welfare is $W^{n d}-C^{h}$ if $\mathrm{R} \& \mathrm{D}$ by the domestic firm is successful and $W^{h d}-C^{h}$ if it is not. With trade, welfare is $W^{f h}$. Thus:

$$
W^{N N}-W^{R}=W^{f h}-p^{h} W^{n d}-\left(1-p^{h}\right) W^{h d}+C^{h}
$$

Solving for $p^{h}$, we see that expected welfare under free trade is higher than under autarky if and only if inequality (40) holds.

\section{C.1.5 R\&D in autarky; (No R\&D, R\&D) with trade}

In autarky, welfare is $W^{n d}-C^{h}$ if R\&D by the domestic firm is successful and $W^{h d}-C^{h}$ if it is not. With trade, welfare is $W^{n h}$ if the foreign firm's R\&D is successful and $W^{f h}$ if it is not. Thus:

$$
W^{N R}-W^{R}=p^{f} W^{n h}+\left(1-p^{f}\right) W^{f h}-\left[p^{h} W^{n d}+\left(1-p^{h}\right) W^{h d}\right]+C^{h}
$$

The RHS is positive if and only if (43) holds.

\section{C.1.6 R\&D in autarky; (R\&D, R\&D) with trade}

In autarky, welfare is $W^{n d}-C^{h}$ if R\&D by the domestic firm is successful and $W^{h d}-C^{h}$ if it is not. With trade, welfare is $W^{n f}-C^{h}=W^{n n}-C^{h}=W^{n d}-C^{h}$ if the domestic firm's $\mathrm{R} \& \mathrm{D}$ is successful and $W^{j h}-C^{h}, j=f, n$, if it is not. Thus we have:

$$
W^{R R}-W^{R}=(1-p)\left[W^{j h}-W^{h d}\right]>0
$$

The inequality follows from Lemma 1.

\footnotetext{
${ }^{17} W^{X Y}$ and $W^{X}$ denote expected welfare under trade and autarky, respectively, with $X(Y)$ the $\mathrm{R} \& \mathrm{D}$ choice of the domestic (foreign) firm. $X, Y=R, N$ where $R(N)$ means (no) R\&D. The same notation is used for $D$ in Section C.2.
} 


\section{C.2 Proof of Proposition 2}

Let us first collect the expressions for emissions. Emissions in each scenario are given by $e_{1} q_{1}$. Thus in scenario $i d, i=h, n$, we have from (19):

$$
E^{i d}=\frac{e_{i}}{\lambda e_{i}^{2}+1}
$$

In scenarios $n f$ and $n n$, emissions are, from (23):

$$
E^{n f}=E^{n n}=\frac{e_{n}}{\lambda e_{n}^{2}+1}
$$

In scenario $j h, j=f, n$, emissions are, from (29):

$$
E^{j h}=\frac{e_{j}\left(e_{j} e_{h}+e_{j}^{2}-e_{h}^{2}\right)}{\lambda e_{j}^{4}+3 e_{j}^{2}-2 e_{h}^{2}}
$$

Before turning to the Proposition, we first establish:

Lemma 3 When the domestic firm has not found the new technology, emissions are higher with free trade than under autarky: $E^{j h}>E^{\text {hd }}$ with $j=f, n$.

Proof. From (C10) and (C12) it is clear that $E^{j h}=E^{h d}$ for $e_{j}=e_{h}$. From (C12):

$$
\frac{d E^{j h}}{d e_{j}}=\frac{-\lambda e_{j}^{6}-2 \lambda e_{j}^{5} e_{h}+3 \lambda e_{j}^{4} e_{h}^{2}+3 e_{j}^{4}-3 e_{j}^{2} e_{h}^{2}-4 e_{j} e_{h}^{3}+2 e_{h}^{4}}{\left(\lambda e_{j}^{4}+3 e_{j}^{2}-2 e_{h}^{2}\right)^{2}}
$$

Setting $e_{j}=e_{h}$ yields:

$$
\left.\frac{d E^{j h}}{d e_{j}}\right|_{e_{j}=e_{h}}=\frac{-2 e_{h}^{4}}{\left(\lambda e_{h}^{4}+e_{h}^{2}\right)^{2}}<0
$$

Thus, when reducing $e_{j}$ below $e_{h}, E^{j h}$ initially rises above $E^{h d}$. However, for lower values of $e_{j}, E^{j h}$ may decline again.

Defining $a \equiv e_{j} / e_{h}, b \equiv \lambda e_{h}^{2}$, we can write (C12) as:

$$
E^{j h}=\frac{e_{j}\left(a^{2}+a-1\right)}{b a^{4}+3 a^{2}-2}
$$

so that

$$
E^{j h}-E^{h d}=e_{h}\left[\frac{\left(a^{3}+a^{2}-a\right)}{b a^{4}+3 a^{2}-2}-\frac{1}{b+1}\right]=\frac{e_{h}\left(a^{2}-1\right)\left(a-a^{2} b+a b-2\right)}{(b+1)\left(b a^{4}+3 a^{2}-2\right)}
$$


The (potentially) positive solutions for $E^{j h}=E^{h d}$ are $e_{j}=e_{h}$ and

$$
a=\frac{1+b \pm \sqrt{b^{2}-6 b+1}}{2}
$$

There are only real solutions for $a$ when $b^{2}-6 b+1 \geq 0$, which is satisfied for $b \leq 3-2 \sqrt{2}$ and $b \geq 3+2 \sqrt{2}$. The first inequality is irrelevant by (18). In case the second inequality holds, the highest possible value for $a$ is for the maximum value of $b$ given by (A5), combined with the "+" sign on the RHS of (C13), so that:

$$
a=\frac{1}{3 \sqrt{5}+5}\left(\frac{3}{2} \sqrt{5}+\frac{7}{2}+\sqrt{\left(\frac{3}{2} \sqrt{5}+\frac{5}{2}\right)^{2}-9 \sqrt{5}-14}\right) \approx 0.61834
$$

Note that (28) can be written as $b a^{3}+a-2>0$. Substituting $a$ from (C14) and $b=\frac{5}{2}+\frac{3}{2} \sqrt{5}$ from (A5), we find $b a^{3}+a-2=0$, so that $(28)$ is violated. Thus $E^{j h}=E^{h d}$ cannot hold and pollution is higher with trade than under autarky.

We will now prove Proposition 2 by examining each possible combination of R\&D decisions in turn. ${ }^{18}$

\section{C.2.1 No R\&D in autarky; (No R\&D, No R\&D) with trade}

In autarky, emissions are $E^{h d}$. With trade, emissions are $E^{f h}$. By Lemma $3, E^{f h}>E^{h d}$.

\section{C.2.2 No R\&D in autarky; (No R\&D, R\&D) with trade}

In autarky, emissions are $E^{h d}$. With trade, emissions are $E^{n h}$ if the foreign firm's R\&D is successful and $E^{f h}$ if it is not. By Lemma $3, E^{j h}>E^{h d}, j=n, f$.

\section{C.2.3 No R\&D in autarky; (R\&D, R\&D) with trade}

In autarky, emissions are $E^{h d}$. With trade, emissions are $E^{n n}=E^{n f}$ if the domestic firm's R\&D is successful and $E^{j h}, j=f, n$, if it is not. We know from subsection C.2.2 that $E^{n n}=E^{n f}>E^{h d}$ and from Lemma 3 that $E^{j h}>E^{h d}$ with $j=f, n$.

\footnotetext{
${ }^{18}$ The expressions for emissions are (C10), (C11) and (C12). To avoid repetition, we will omit references to these equations in the following analysis.
} 


\section{C.2.4 R\&D in autarky; (No R\&D, No R\&D) with trade}

In autarky, emissions are $E^{n d}$ if R\&D is successful and $E^{h d}$ if it is not. With trade, emissions are $E^{f h}$ with $j=f$. Thus:

$$
D^{N N}-D^{R}=\frac{1}{2} \lambda\left(E^{f h}\right)^{2}-\frac{1}{2} \lambda\left[p^{h}\left(E^{n d}\right)^{2}+\left(1-p^{h}\right)\left(E^{h d}\right)^{2}\right]
$$

Solving for $p^{h}$, we see that the expected pollution damage under free trade is greater than under autarky if and only if (42) holds.

\section{C.2.5 R\&D in autarky; (No R\&D, R\&D) with trade}

In autarky, emissions are $E^{n d}$ if $\mathrm{R} \& \mathrm{D}$ is successful and $E^{h d}$ if it is not. With trade, emissions are $E^{n h}$ if the foreign firm's R\&D is successful and $E^{f h}$ if it is not. Thus we have:

$$
\begin{aligned}
D^{N R}-D^{R}= & \frac{1}{2} \lambda\left[p^{f}\left(E^{n h}\right)^{2}+\left(1-p^{f}\right)\left(E^{f h}\right)^{2}-p^{h}\left(E^{n d}\right)^{2}-\left(1-p^{h}\right)\left(E^{h d}\right)^{2}\right]= \\
& \frac{1}{2} \lambda\left[p^{h}\left[\left(E^{n h}\right)^{2}-\left(E^{n d}\right)^{2}\right]+\left(1-p^{f}\right)\left[\left(E^{f h}\right)^{2}-\left(E^{h d}\right)^{2}\right]+\left(p^{f}-p^{h}\right)\left[\left(E^{n h}\right)^{2}-\left(E^{h d}\right)^{2}\right]\right]
\end{aligned}
$$

By Lemma 3, a sufficient condition for $D^{N R}>D^{R}$ is (41).

\section{C.2.6 R\&D in autarky; (R\&D, R\&D) with trade}

In autarky, emissions are $E^{n d}$ if R\&D is successful and $E^{h d}$ if it is not. With trade, emissions are $E^{n n}=E^{n f}=E^{n d}$ if the domestic firm's R\&D is successful and $E^{j h}, j=$ $f, n$, if it is not. Thus we have:

$$
\begin{gathered}
D^{R R}-D^{R}= \\
\frac{1}{2} \lambda\left[p^{h}\left(E^{n d}\right)^{2}+p^{f}\left(1-p^{h}\right)\left(E^{n h}\right)^{2}+\left(1-p^{h}\right)\left(1-p^{f}\right)\left(E^{f h}\right)^{2}-p^{h}\left(E^{n d}\right)^{2}-\left(1-p^{h}\right)\left(E^{h d}\right)^{2}\right] \\
=\frac{1}{2} \lambda\left(1-p^{h}\right)\left[p^{f}\left(E^{n h}\right)^{2}+\left(1-p^{f}\right)\left(E^{f h}\right)^{2}-\left(E^{h d}\right)^{2}\right]>0
\end{gathered}
$$

The inequality follows from Lemma 3. 


\section{References}

[1] Antweiler, W., B.R. Copeland and M.S. Taylor (2001), "Is free trade good for the environment?", American Economic Review 91: 877-908.

[2] Biglaiser, G. and J.K. Horowitz (1995), "Pollution regulation and incentives for pollution-control research", Journal of Economics and Management Strategy 3: 663-684.

[3] Binswanger, M. (2001), "Technological progress and sustainable development: what about the rebound effect?", Ecological Economics 36 : 119-132.

[4] Bréchet, T. and S. Ly (2013), "The many traps of green technology promotion", Environmental Economics and Policy Studies 15: 73-91.

[5] Canton, J. (2008), "Redealing the cards: How an eco-industry modifies the political economy of environmental taxes", Resource and Energy Economics 30: 295315.

[6] Cole, M.A. and R.J.R. Elliott (2003), "Determining the trade-environment composition effect: The role of capital, labor and environmental regulations", Journal of Environmental Economics and Management 46: 363-383.

[7] David, M., A.D. Nimubona and B. Sinclair-Desgagné (2011), "Emission taxes and the market for abatement goods and services", Resource and Energy Economics 33: 179-191.

[8] De Melo, J. and M. Vijil (2014), "Barriers to trade in environmental goods and environmental services: How important are they? How much progress at reducing them?", Nota di lavoro 36.2014, FEEM.

[9] Feess, E. and G. Muehlheusser (2002), "Strategic environmental policy, clean technologies and the learning curve", Environmental and Resource Economics 23: 149166.

[10] Fisher-Vanden, K. and M.S. Ho (2010), "Technology, development, and the environment", Journal of Environmental Economics and Management 59: 94-108. 
[11] Fischer, C., I.W.H. Parry and W.A. Pizer (2003), "Instrument choice for environmental protection when technological innovation is endogenous", Journal of Environmental Economics and Management 45: 523-545.

[12] Greaker, M. (2006), "Spillovers in the development of new pollution abatement technology: A new look at the Porter hypothesis", Journal of Environmental Economics and Management 56: 411-420.

[13] Greaker, M. and K.E. Rosendahl (2008), "Environmental policy with upstream pollution abatement technology firms", Journal of Environmental Economics and Management 56: 246-259.

[14] Hamwey, R. (2005). Environmental Goods: Where Do the Dynamic Trade Opportunities for Developing Countries Lie? Working paper prepared to support discussions at the Hong Kong Trade and Development Symposium and the sixth WTO ministerial Conference in Hong Kong in December 2005.

[15] Hanley, N., P. McGregor, J.K. Swales and K. Turner (2009), "Do increases in energy efficiency improve environmental quality and sustainability?", Ecological Economics 68: 692-709.

[16] Jaffe, A.B., Newell, R.G., Stavins, R.N. (2003), "Technological change and the environment", in K.-G. Maler and J.R. Vincent (eds.), Handbook of Environmental Economics, Vol I, 461-516.

[17] Khazzoom, D.J. (1980), "Economic implications of mandated efficiency standards for household appliances", Energy Journal 1: 21-40.

[18] Laffont, J.J. and J. Tirole (1996), "Pollution permits and environmental innovation", Journal of Public Economics 62: 127-140.

[19] Lovely, M. and D. Popp (2011), "Trade, technology, and the environment: Does access to technology promote environmental regulation?", Journal of Environmental Economics and Management 61: 16-35.

[20] Managi, S., A. Hibiki and T. Tsurumi (2009), "Does trade openness improve environmental quality?", Journal of Environmental Economics and Management 58: 346-363. 
[21] Milliman, S.R. and R. Prince (1989), "Firms incentives to promote technological change in pollution control", Journal of Environmental Economics and Management 17: 247-265.

[22] Nimubona, A.-D. (2012), "Pollution policy and trade liberalization of environmental goods", Environmental and Resource Economics 53: 323-346.

[23] OECD (2003), Environmental goods and services: The benefits of further global trade liberalisation, OECD, Paris.

[24] OECD (2005), Trade that benefits the environment and development: Opening markets for environmental goods and services, OECD, Paris.

[25] Parry, W. (1995), "Optimal pollution taxes and endogenous technological progress", Resource and Energy Economics 17: 69-85.

[26] Parry, W. (1998), "Pollution regulation and the efficiency gains from technological innovation", Journal of Regulatory Economics 14: 229-254.

[27] Perino, G. (2010), "Technology diffusion with market power in the upstream industry", Environmental and Resource Economics 46: 403-428.

[28] Requate, T. (2005a), "Dynamic incentives by environmental policy instrumentsa survey", Ecological Economics 54: 175-195.

[29] Requate, T. (2005b), "Timing and commitment of environmental policy, adoption of new technology, and repercussions on R\&D", Environmental and Resource Economics 31: 175-199.

[30] Saunders, H.D (2000), "A view from the macro side: Rebound, backfire, and Khazzoom-Brookes", Energy Policy 28: 439-449.

[31] Sinclair-Desgagné, B. (2008), "The environmental goods and services industry", International Review of Environmental and Resource Economics 2: 69-99.

[32] UNEP, ITC and ICTSD (2012), "Trade and environment briefings: Trade in environmental goods", ICTSD Programme on Global Economic Policy and Institutions; Policy Brief No. 6; International Cen- 
tre for Trade and Sustainable Development, Geneva, Switzerland, available at: http://www.ictsd.org/sites/default/files/research/2012/06/trade-inenvironmental-goods.pdf.

[33] USTR (2014), "Remarks by United States Trade Representative Michael Froman announcing new talks towards increased trade in environmental goods", United States Trade Representative, 24 January 2014, available at: https://ustr.gov/about-us/policy-offices/press-office/pressreleases/2014/January/USTR-Froman-remarks-on-new-talks-towards-increasedtrade-environmental-goods

[34] World Trade Organization (2001), Ministerial Declaration, Ministerial Conference, Fourth Session, Doha, 9 - 14 November 2001.

[35] Zhang, Z.X. (2013), "Trade in environmental goods, with focus on climate-friendly goods and technologies", in G. van Calster and D. Prévost (eds), Research Handbook on Environment, Health and the WTO, Edward Elgar, Northampton (MA), pp. 673-699. 